\title{
Jaundice as a Rare Manifestation of Epstein-Barr Virus Primary Infection
}

\author{
Lígia Rodrigues Santos $^{1}$, Margarida Silva Cruz $^{1}$, Rita Veiga Ferraz ${ }^{2}$, Vera Ferraz Moreira ${ }^{1}$, Alice Castro ${ }^{1}$ \\ 1. Internal Medicine, Centro Hospitalar do Tâmega e Sousa, Penafiel, PRT 2. Infectious Diseases, Centro Hospitalar do \\ Tâmega e Sousa, Penafiel, PRT
}

Corresponding author: Lígia Rodrigues Santos, ligia.santos15@hotmail.com

\begin{abstract}
Epstein-Barr virus (EBV) primary infection usually presents with classic symptoms of infectious mononucleosis (IM) like fever, lymphadenopathies and tonsillopharyngitis. Liver damage is frequently mild and self-limited and there are only a few cases of severe EBV-induced cholestatic hepatitis and jaundice reported in the literature. The authors present the case of a 22 -year-old woman who was admitted with acute fever and jaundice. Physical examination revealed posterior cervical lymphadenopathies and painful hepatosplenomegaly. Laboratorial findings suggested an obstructive cause for jaundice but ultrasound and magnetic resonance cholangiopancreatography excluded biliary duct pathology. Heterophile antibodies were negative but EBV-specific antibodies revealed isolated positive viral capsid antigen (VCA) immunoglobin (Ig) M suggesting the diagnosis of early phase of EBV primary infection. The diagnosis of EBV-induced cholestatic hepatitis was confirmed after identification of EBV deoxyribonucleic acid (DNA) in blood and by liver biopsy. Supportive management was provided and, despite an initial clinical deterioration, the patient had a favorable outcome. EBV is a virus with a high prevalence worldwide, mainly subclinical, and jaundice is a rare manifestation of the infection. Although the majority of the patients recover without sequelae, progression to liver failure has been described and a careful assessment for complications is mandatory. Therefore, EBV infection should be included in the comprehensive differential diagnosis of jaundice in all age groups.
\end{abstract}

Review began 05/28/2021 Review ended 06/02/2021 Published 06/12/2021

\section{(๑) Copyright 2021}

Rodrigues Santos et al. This is an open access article distributed under the terms of the Creative Commons Attribution License CC-BY 4.0., which permits unrestricted use, distribution, and reproduction in any medium, provided the original author and source are credited.
Categories: Internal Medicine, Gastroenterology, Infectious Disease

Keywords: cholestasis, epstein-barr virus, hepatitis, infectious mononucleosis, jaundice

\section{Introduction}

Epstein-Barr virus (EBV) is a common herpesvirus with usually asymptomatic primary infection, occurring between 10 and 30 years old in developed countries [1, 2]. Increasing age seems to enhance the likelihood of symptomatic infection. Classic presentation as infectious mononucleosis (IM) includes fever, tonsillopharyngitis and lymphadenopathies [1, 2].

However, EBV can hypothetically affect any organ, with hematologic and liver abnormalities occurring in a large number of patients. Up to $80-90 \%$ of the patients have transaminases elevation, which is frequently mild, asymptomatic and self-limited, however, severe hepatitis and liver failure have been described especially in immunosuppressed patients [3-5]. Significant cholestasis and jaundice are rare with an estimated incidence below 5\% [4-7]. Only a few cases of EBV-induced cholestasis have been reported, with or without associated features of IM [8-14].

\section{Case Presentation}

A 22-year-old woman presented in the Emergency Department with fever, abdominal pain, jaundice and choluria. No nausea, vomiting, gastrointestinal changes or other associated symptoms were reported. Three days before presentation a self-limited upper respiratory tract infection with throat pain, hoarseness and nasal congestion was mentioned. There was no history of illicit drug use, recent travel, contact with ill persons, hepatotoxic products consumption or other relevant epidemiological factors. Past personal or familiar medical history was unremarkable.

On physical examination the patient was febrile, hemodynamically stable, had skin and scleral icterus, pericentimetric posterior cervical lymphadenopathies and painful hepatosplenomegaly. Initial laboratorial tests revealed lymphomonocytosis (60\% lymphocytes and 17\% monocytes), mild thrombocytopenia, inflammatory markers elevation and direct hyperbilirubinemia with cytocholestasis (Table 1). Albumin and coagulation tests were within normal values. Urine tested positive for bilirubin and urobilinogen. Paul Bunnell Davidson test was negative. 


\section{Cureus}

\begin{tabular}{|c|c|c|}
\hline Laboratory findings & Baseline & Reference range \\
\hline Hemoglobin (g/dl) & 13.4 & $12-15$ \\
\hline WBC (counts $/ \mu \mathrm{L}$ ) & 9610 & $4500-11,000$ \\
\hline Lymphocytes (counts $/ \mu \mathrm{L}$ ) & 5766 & $1500-4000$ \\
\hline Monocytes (counts/ $\mu \mathrm{L}$ ) & 1634 & $200-800$ \\
\hline Platelet (counts/ $\mu \mathrm{L}$ ) & 138,000 & $150,000-400,000$ \\
\hline ESR (mm/h) & 38 & $0-20$ \\
\hline CRP (mg/L) & 175 & $<5$ \\
\hline Total bilirubin (mg/dL) & 6.6 & $<1.0$ \\
\hline Direct bilirubin (mg/dL) & 4.7 & $<0.2$ \\
\hline $\operatorname{ALP}(\mathrm{U} / \mathrm{L})$ & 498 & 34-104 \\
\hline GGT (U/L) & 78 & $<32$ \\
\hline ALT (U/L) & 105 & $<31$ \\
\hline AST (U/L) & 167 & $<31$ \\
\hline $\mathrm{LDH}(\mathrm{U} / \mathrm{L})$ & 2327 & $266-500$ \\
\hline
\end{tabular}

\section{TABLE 1: Baseline laboratory tests}

ALP, alkaline phosphatase; ALT, alanine transaminase; AST, aspartate transaminase; CRP, C-reactive protein; ESR, erythrocyte sedimentation rate; GGT, gamma-glutamyl transpeptidase; LDH, lactate dehydrogenase; WBC, white blood cells.

Abdominal ultrasonography revealed heterogenous enlarged liver, mild common biliary duct dilatation without cholelithiasis and homogeneous splenomegaly (Figure 1). Portal vein thrombosis was excluded on doppler examination.
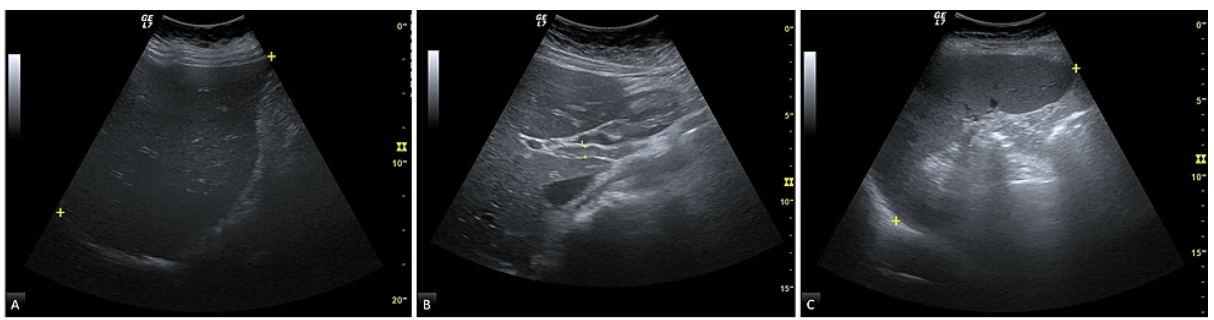

\section{FIGURE 1: Abdominal ultrasonography}

A: Enlarged liver, $191 \mathrm{~mm}$, without focal lesions. B: Common biliary duct dilatation, $6 \mathrm{~mm}$, without cholelithiasis. C: Splenomegaly, 154mm. Structures marked between the yellow crosses.

In the following days after admission, a clinical worsening was observed with fatigue, persistent fever and diffuse itchy maculopapular rash including palms and plants. Cholestatic enzymes continued to rise with peak on the 10th day (Table 2). 


\section{Cureus}

\begin{tabular}{|c|c|c|c|c|}
\hline Laboratory findings & Day 1 & Day 7 & Day 10 & Reference range \\
\hline Total bilirubin (mg/dL) & 8.6 & 12.8 & 13.0 & $<1.0$ \\
\hline Direct bilirubin (mg/dL) & 5.3 & 8.1 & 8.1 & $<0.2$ \\
\hline $\operatorname{ALP}(\mathrm{U} / \mathrm{L})$ & 528 & 845 & 1439 & 34-104 \\
\hline GGT (U/L) & 85 & 203 & 427 & $<32$ \\
\hline ALT (U/L) & 102 & 70 & 103 & $<31$ \\
\hline AST (U/L) & 172 & 97 & 120 & $<31$ \\
\hline
\end{tabular}

\section{TABLE 2: Evolution of liver biochemistry tests during the first days}

ALP, alkaline phosphatase; ALT, alanine transaminase; AST, aspartate transaminase; GGT, gamma-glutamyl transpeptidase.

Multiple blood and urine cultures were negative. Nonimmune hemolytic anemia (hemoglobin level of $11.2 \mathrm{~g} / \mathrm{dL}$, reference range (RR) $12-15 \mathrm{~g} / \mathrm{dL}$; reticulocyte index above 2.5 without significant peripherical blood smear changes, low haptoglobin, negative antiglobulin tests) and coagulopathy have emerged (international normalized ratio of 1.7). There was ferritin and triglycerides elevation (>1500ng/mL, RR 20-250ng/mL; and $233 \mathrm{mg} / \mathrm{dL}, \mathrm{RR}<150 \mathrm{mg} / \mathrm{dL}$; respectively) and mild fibrinogen consumption (185mg/dL, RR 200-400mg/dL). Not all diagnostic criteria for hemophagocytic lymphohistiocytosis (HLH) were fulfilled.

Further laboratorial investigation revealed a positive EBV viral capsid antigen (VCA) immunoglobin (Ig) M; VCA and Epstein-Barr nuclear antigen (EBNA) IgG were both negative. Serologic tests for hepatitis A, B or C viruses, cytomegalovirus (CMV), toxoplasma and human immunodeficiency virus (HIV) were negative for recent or active infection. Antinuclear, antineutrophil cytoplasmic, anti-smooth muscle, antimitochondrial and anti-liver-kidney microsomal antibodies were also negative. Thoracic and abdominal computerized tomography scan revealed pericentimetric axillary, retroperitoneal, inguinal and iliac lymphadenopathies with no other lesions. Magnetic resonance cholangiopancreatography was unremarkable.

EBV deoxyribonucleic acid (DNA) was detected by polymerase chain reaction (PCR, 3.7x105 copies/ml). Liver biopsy was performed and histopathological findings were compatible with inflammatory infiltration of the liver by epithelioid granulomas and sinusoidal lymphocytosis (Figure 2) and the diagnosis of cholestatic hepatitis due to EBV primary infection was confirmed.
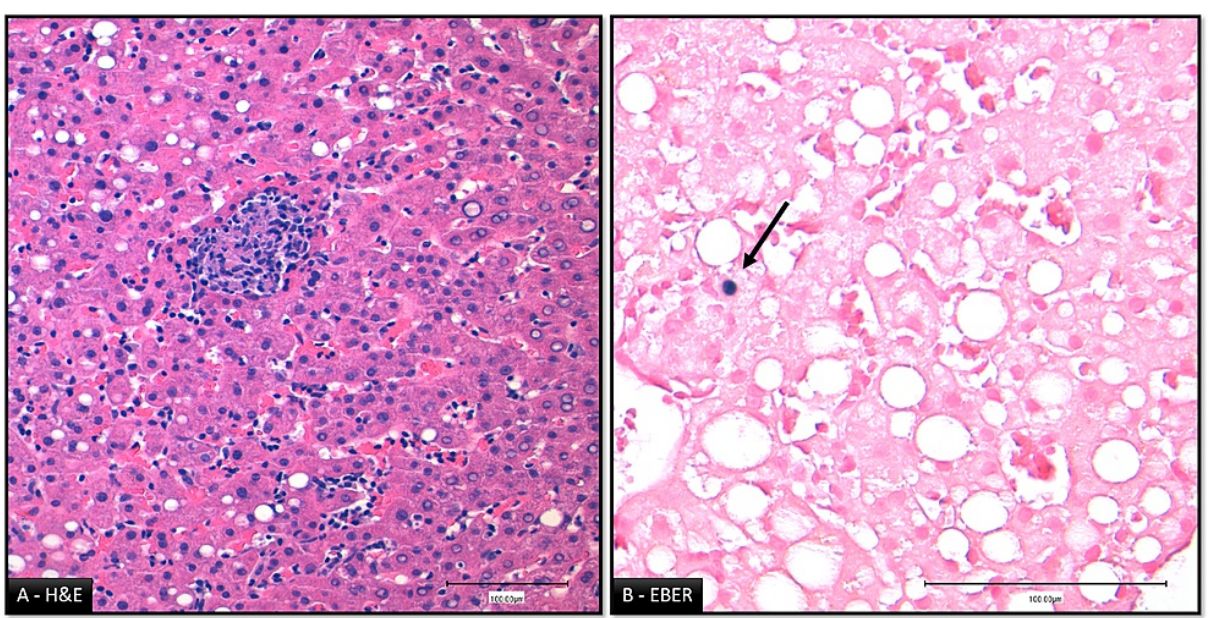

\section{FIGURE 2: Liver histopathologic findings}

A: Liver parenchyma with mild steatosis, histiocytic aggregates outlining epithelioid granulomas and sinusoidal lymphocytosis. No hepatocellular necrosis was found. B: Immunohistochemical staining for Epstein-Barr virus (EBV) by EBV encoding region (EBER) revealed positivity of few hepatocytes (arrow).

The patient gradually improved under supportive treatment. Follow-up tests three months after discharge revealed normal liver tests and EBV seroconversion (Table 3). 


\section{Cureus}

\begin{tabular}{|c|c|c|c|}
\hline Laboratory findings & 1st month & 3rd month & Reference range \\
\hline Total bilirubin (mg/dL) & 3.1 & 0.6 & $<1.0$ \\
\hline Direct bilirubin (mg/dL) & 1.5 & - & $<0.2$ \\
\hline $\operatorname{ALP}(\mathrm{U} / \mathrm{L})$ & 129 & 87 & 34-104 \\
\hline GGT (U/L) & 33 & 18 & $<32$ \\
\hline ALT (U/L) & 64 & 28 & $<31$ \\
\hline AST (U/L) & 45 & 23 & $<31$ \\
\hline
\end{tabular}

TABLE 3: Evolution of liver biochemistry tests within follow-up

ALP, alkaline phosphatase; ALT, alanine transaminase; AST, aspartate transaminase; GGT, gamma-glutamyl transpeptidase.

\section{Discussion}

Jaundice is a rare presentation of EBV primary infection. Investigation of an obstructive jaundice is mainly based on abdominal imaging, as differential diagnosis includes extrahepatic cholestasis. After its exclusion by ultrasonography, or more effectively by magnetic resonance cholangiopancreatography, early recognition of the potential causes of intrahepatic cholestasis injury, in which EBV must be considered, is essential to a correct diagnosis and management [10].

In the reported case, heterophile antibodies were negative. Despite its valuable use for point-of-care diagnosis, false-negative results can occur, especially at the initial clinical presentation [2]. EBV specific IgM antibodies were positive, documenting primary infection. Other causes were excluded, namely other viruses, drugs, autoimmune and infiltrative diseases [15].

At admission, the patient had an obstructive jaundice with direct hyperbilirubinemia and choluria. Posteriorly, we might assume that the virus-induced nonimmune hemolytic anemia contributed to jaundice as the hyperbilirubinemia became mixed. Cutaneous rash can be associated with EBV infection in $5 \%$ of patients, especially when antibiotics are prescribed [14, 16]. In this report, no antibiotic therapy has been used prior to maculopapular erythema installation.

The diagnosis of HLH was considered owing the severe documented immune activation. This aggressive and life-threatening entity should be promptly recognized and treated, as diagnosis delay can be associated with poor outcome. However, only four of the criteria were fulfilled (diagnosis is made if five of the following findings are present: fever $\geqslant 38.5^{\circ} \mathrm{C}$, splenomegaly, significant peripheral blood cytopenia, hypertriglyceridemia or/and hypofibrinogenemia, hemophagocytosis evidence, low natural killer cell activity, high ferritin level and soluble CD25; or in the presence of heterozygosity for HLH-associated mutations with concurrent clinical features) [17].

The pathogenesis of cholestasis in the setting of EBV primary infection is not completely understood and several mechanisms have been proposed. It is thought that EBV infection leads to cytokine increase with inflammation and disruption of canalicular function or to direct damage of hepatic cells by autoantibodymediated oxidative damage $[3,6,18]$. Once suspected, a detailed medical history and physical examination should be performed, and serologic markers should be measured [3, 8, 9].

\section{Conclusions}

The final diagnosis of EBV-related jaundice requires a high level of suspicion hence the importance of reporting this rare complication of EBV infection. The management of EBV infection is mainly supportive and prognosis is usually favorable with complete recovery in several weeks. However, progression to liver failure has been described and a careful assessment should be made to prevent that.

\section{Additional Information \\ Disclosures}

Human subjects: Consent was obtained or waived by all participants in this study. Conflicts of interest: In compliance with the ICMJE uniform disclosure form, all authors declare the following: Payment/services info: All authors have declared that no financial support was received from any organization for the submitted work. Financial relationships: All authors have declared that they have no financial relationships at present or within the previous three years with any organizations that might have an 
interest in the submitted work. Other relationships: All authors have declared that there are no other relationships or activities that could appear to have influenced the submitted work.

\section{Acknowledgements}

The authors would like to thank the Department of Infectious Diseases and the Department of Anatomic Pathology of the Centro Hospitalar Universitário de São João for the study support on this case and the provision of liver biopsy images.

\section{References}

1. Bunchorntavakul C, Reddy KR: Epstein-Barr virus and cytomegalovirus infections of the liver. Gastroenterol Clin North Am. 2020, 49:331-346. 10.1016/j.gtc.2020.01.008

2. Cohen JI: Epstein-Barr virus infection. N Engl J Med. 2000, 343:481-492. 10.1056/NEJM200008173430707

3. Drebber U, Kasper HU, Krupacz J, et al.: The role of Epstein-Barr virus in acute and chronic hepatitis . J Hepatol. 2006, 44:879-885. 10.1016/j.jhep.2006.02.006

4. Kofteridis DP, Koulentaki M, Valachis A, Christofaki M, Mazokopakis E, Papazoglou G, Samonis G: Epstein Barr virus hepatitis. Eur J Intern Med. 2011, 22:73-76. 10.1016/j.ejim.2010.07.016

5. Markin RS: Manifestations of Epstein-Barr virus-associated disorders in liver . Liver. 1994, 14:1-13. 10.1111/j.1600-0676.1994.tb00001.x

6. Negro F: The paradox of Epstein-Barr virus-associated hepatitis. J Hepatol. 2006, 44:839-841. 10.1016/j.jhep.2006.03.002

7. Noor A, Panwala A, Forouhar F, Wu GY: Hepatitis caused by herpes viruses: a review . J Dig Dis. 2018, 19:446-455. 10.1111/1751-2980.12640

8. Edoute Y, Baruch Y, Lachter J, Furman E, Bassan L, Assy N: Severe cholestatic jaundice induced by EpsteinBarr virus infection in the elderly. J Gastroenterol Hepatol. 1998, 13:821-824. 10.1111/j.14401746.1998.tb00739.x

9. Hinedi TB, Koff RS: Cholestatic hepatitis induced by Epstein-Barr virus infection in an adult . Dig Dis Sci. 2003, 48:539-541. 10.1023/a:1022592801060

10. Khoo A: Acute cholestatic hepatitis induced by Epstein-Barr virus infection in an adult: a case report . J Med Case Rep. 2016, 10:75. 10.1186/s13256-016-0859-x

11. Losavio AD, Te HS: Epstein-barr virus: an unusual cause of cholestatic hepatitis in older adults . Gastroenterol Hepatol (N Y). 2007, 3:101-105.

12. Salva I, Silva IV, Cunha F: Epstein-Barr virus-associated cholestatic hepatitis. BMJ Case Rep. 2013, 2013:bcr2013202213. 10.1136/bcr-2013-202213

13. Shkalim-Zemer V, Shahar-Nissan K, Ashkenazi-Hoffnung L, Amir J, Bilavsky E: Cholestatic hepatitis induced by Epstein-Barr virus in a pediatric population. Clin Pediatr (Phila). 2015, 54:1153-1157. $10.1177 / 0009922815570618$

14. Uluğ M, Celen MK, Ayaz C, Geyik MF, Hoşoğlu S: Acute hepatitis: a rare complication of Epstein-Barr virus (EBV) infection. J Infect Dev Ctries. 2010, 4:668-673. 10.3855/jidc.871

15. Obel N, Høier-Madsen M, Kangro H: Serological and clinical findings in patients with serological evidence of reactivated Epstein-Barr virus infection. APMIS. 1996, 104:424-428. 10.1111/j.1699-0463.1996.tb00737.x

16. Lawee D: Mild infectious mononucleosis presenting with transient mixed liver disease: case report with a literature review. Can Fam Physician. 2007, 53:1314-1316.

17. Rouphael NG, Talati NJ, Vaughan C, Cunningham K, Moreira R, Gould C: Infections associated with haemophagocytic syndrome. Lancet Infect Dis. 2007, 7:814-822. 10.1016/S1473-3099(07)70290-6

18. Shaukat A, Tsai HT, Rutherford R, Anania FA: Epstein-Barr virus induced hepatitis: an important cause of cholestasis. Hepatol Res. 2005, 33:24-26. 10.1016/j.hepres.2005.06.005 